\title{
The Crystal Structure of ScOF
}

\author{
B O H O L M B ER G
}

Institute of Inorganic and Physical Chemistry, University of Stockholm, Stockholm, Sweden

\begin{abstract}
Scandium oxide fluoride, ScOF, crystallizes in the monoclinic space group $P 2_{1} / c$. There are four formula units in the unit cell with the dimensions $a=5.1673 \pm 0.0005, b=5.1466 \pm 0.0005$, $c=5.2475 \pm 0.0008 \AA, \beta=99^{\circ} 42^{\prime} \pm 5^{\prime}$. The structure has been refined by the method of least squares from three dimensional Weissen. berg data. Evidence is presented for the distraction between oxygen atoms and fluorine atoms. Each scandium atom is surrounded by four oxygen and three fluorine atoms, the average distances being 2.10 and $2.20 \AA$, respectively. The coordination polyhedron and the linking of the polyhedra are the same as in the monoclinic modification of $\mathrm{ZrO}_{2}$.
\end{abstract}

\section{EXPERIMENTAL}

An intermediate phase in the system $\mathrm{Sc}_{2} \mathrm{O}_{3}-\mathrm{ScF}_{3}$ has been identified by $\mathrm{X}$-ray powder analysis of samples prepared by heating mixtures of the two components at $1000^{\circ} \mathrm{C}$ for three days in sealed platinum tubes. $\mathrm{ScF}_{3}$ was made from $\mathrm{Sc}_{2} \mathrm{O}_{3}$ (L. Light \& Co., Ltd. $99.9 \%$ pure) by dissolving in p.a. hydrofluoric acid and evaporating to dryness. As the 1:1 preparation gave a mono-phasic Guinier powder pattern, it was concluded that the composition of the phase is ScOF. The powder pattern, Table 2, could be indexed with the monoclinic unit cell reported in Table 1.

Table 1. Crystallographic data for ScOF.

Symmetry

Unit cell

Systematically absent reflections

Space group Unit cell content

Density, observed calculated

\begin{tabular}{llc} 
& ScOF & \multicolumn{1}{c}{$\mathrm{ZrO}_{2}(1,2)$} \\
$a$ & $5.1673 \pm 0.0005 \AA$ & monoclinic \\
$b$ & $5.1466 \pm 0.0005$ & $5.1454 \pm 0.0005 \AA(3)$ \\
$c$ & $5.2475 \pm 0.0008$ & $5.2075 \pm 0.0005$ \\
$\beta$ & $9^{\circ} 42^{\prime} \pm 5^{\prime}$ & $5.3107 \pm 0.0005$
\end{tabular}

$0 k 0$ with $k=2 n+1$

h0l with $l=2 n+1$

$$
4 \mathrm{ScOF} P 2_{1} / c \quad \text { (No. 14) } 4 \mathrm{ZrO}_{2}
$$

$3.84 \mathrm{~g} / \mathrm{cm}^{3}$

$3.86 \mathrm{~g} / \mathrm{cm}^{3}$ 
The X-ray density of $3.86 \mathrm{~g} / \mathrm{cm}^{3}$, calculated with $4 \mathrm{ScOF}$ in the unit cell, is in good agreement with the observed density $3.84 \mathrm{~g} / \mathrm{cm}^{3}$, determined from the weight-loss in benzene.

The sample consisted of plate-like colourless crystals. The single crystal X-ray examinations revealed that they were all twinned on (100) and had their longest extension along the $c$ axis.

Weissenberg patterns were taken about the $c$ axis with nickel filtered copper radiation. Intensities were recorded by the multiple film technique. The plate used had the dimensions $0.031 \times 0.023 \times 0.010 \mathrm{~mm}$. The intensities of the reflections from one of the twins were visually estimated by comparison with a set of timed exposures of a selected reflection. The data were not corrected for absorption. An estimation of its influence on the data was undertaken by calculation of the absorption in an untwinned crystal of the same size.

\section{DETERMINATION AND REFINEMENT OF THE STRUCTURE}

The single crystal examination confirmed the chosen unit cell and gave the following systematic absences: $h 0 l$ with $l=2 n+1$ and $0 k 0$ with $k=2 n+1$ determining the space group to $P 2_{1} / c$.

A comparison of the derived crystallographic data for ScOF with those reported for monoclinic $\mathrm{ZrO}_{2},{ }^{1-3}$ Table 1, suggested that the two structures are isotypic. Some simple calculations showed that this was true and furthermore that both compounds had approximately the same positional parameters.

The atoms in $\mathrm{ZrO}_{2}$ are in four-fold positions and $\mathrm{McCullough}$ and Trueblood $^{2}$ found that the oxygen atoms in the two sets have different functions in the structure. The oxygen atoms $\mathrm{O}_{\mathrm{I}}$ are coordinated to three and the atoms $\mathrm{O}_{11}$ to four zirconium atoms. In ScOF the possibility existed that these two

Table 2. ScOF Guinier powder pattern, $\mathrm{CuK} \alpha_{1}$ radiation.

$\begin{array}{cccc}\text { Intensity } & \sin ^{2} \theta_{\text {obs }} & h k l & \sin ^{2} \theta_{\text {calc }} \\ \text { m } & 0.02292 & 100 & 0.02287 \\ \text { m } & 0.04461 & 011 & 0.04457 \\ \text { w } & 0.04531 & 110 & 0.04527 \\ \text { st } & 0.05989 & 111 & 0.05986 \\ \text { st } & 0.07507 & 111 & 0.07503 \\ \text { m } & 0.08876 & 002 & 0.08870 \\ \text { vw } & 0.08958 & 020 & 0.08959 \\ \text { vvw } & 0.11098 & 012 & 0.11110 \\ \text { vvw } & 0.11232 & 120 & 0.11246 \\ \text { w } & 0.11391 & 210 & 0.11387 \\ \text { vvw } & 0.11885 & 112 & 0.11883 \\ \text { st } & 0.12100 & 211 & 0.12087 \\ \text { m broad } & 0.12699 & 102 & 0.12672 \\ \text { vvw } & 0.14241 & 121 & 0.12707 \\ \text { m } & 0.14912 & 121 & 0.14223 \\ \text { m } & 0.15113 & 112 & 0.14914 \\ \text { w } & 0.17219 & 211 & 0.15122 \\ \text { st } & 0.17823 & 0.17223 \\ \text { m } & 0.18111 & 022 & 0.17829 \\ \text { m } & 0.18601 & 220 & 0.18107 \\ \text { w } & 0.18806 & \overline{1} 22 & 0.18599 \\ \text { w } & 0.20578 & 300 & 0.18807 \\ \text { m } & & 0.20581\end{array}$

Acta Chem. Scand. 20 (1966) No. 4 
Table 3. Final atomic parameters in ScOF for different fluorine and oxygen arrangement and atomic parameters in $\mathrm{ZrO}_{2}(8)$.

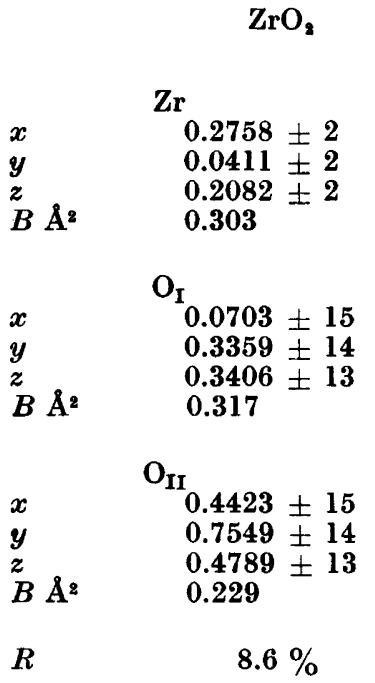

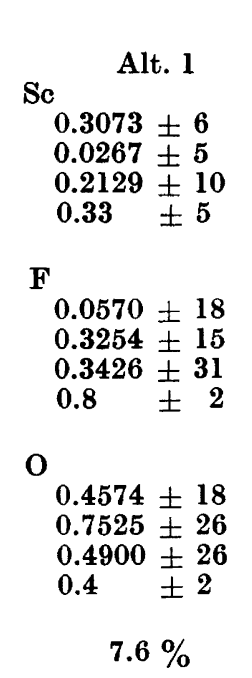

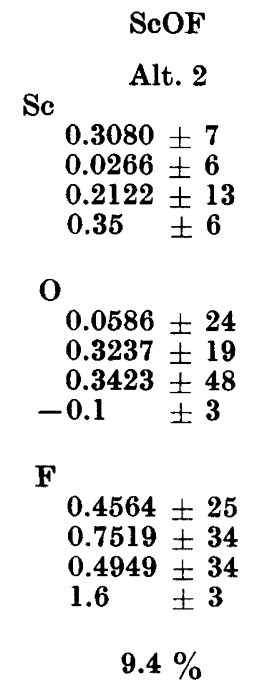

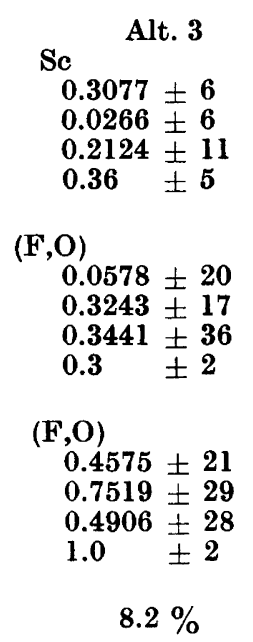

sets consisted of one fluorine and one oxygen set. In order to determine if the structure was ordered in such a way, it was refined by the method of least squares from the $h k 0, h k 1$, and $h k 2$ Weissenberg data using the FACIT EDB computer program. ${ }^{4}$ Of the 162 possible reflections, 120 were observed, but 10 of these, too intense with the exposure times employed to allow a correct estimation of their intensities, were consequently excluded from the refinement.

Three different refinements were performed starting from the $\mathrm{ZrO}_{2}$ structure, viz. one with fluorine atoms in the $\mathrm{O}_{1}$ position, one with oxygen atoms in the $O_{r}$ position and one with the oxygen and fluorine atoms randomly distributed over the $\mathrm{O}_{1}$ and $\mathrm{O}_{\mathrm{II}}$ positions. In all the cases the refinement of the nine positional parameters, the three isotropic temperature factors and the three scale factors were based on the scattering factors for $\mathrm{Sc}^{3+}$, $\mathrm{F}^{-},{ }^{5}$ and $\mathrm{O}^{2-},{ }^{6}$ corrected with the real part of the dispersion. The weighting scheme given by Hughes ${ }^{7}$ was used.

In Table 3 the resulting atomic parameters and corresponding $R$ values (for 110 reflections) are given for the three alternatives of anion arrangement together with the coordinates of the monoclinic $\mathrm{ZrO}_{2}$. Although the positional parameters of the three alternatives are the same within the standard deviations, the first alternative gives a better fit to the observed data as shown by the lower $R$ value and the lower standard deviations. In Table 4, a comparison is given between the observed structure factors and those calculated with the atomic parameters for this choice. The most pronounced divergence of the three alternatives is demonstrated in the values of the temperature factors of the anions which strongly indicate that the fluorine atoms are in the $\mathrm{O}_{\mathrm{I}}$ position. 
Table 4. Observed and calculated structure factors for ScOF, $(*$ excluded from the refinements).

\begin{tabular}{|c|c|c|c|c|c|c|c|c|}
\hline$h k$ & $\left|\boldsymbol{F}_{\mathrm{c}}\right|$ & $\left|\boldsymbol{F}_{\mathrm{o}}\right|$ & $h k$ & $\left|F_{\mathrm{c}}\right|$ & $\left|F_{\mathrm{o}}\right|$ & $h k$ & $\left|\hat{i^{\prime}} \mathrm{c}\right|$ & $\left|\boldsymbol{F}_{\mathrm{o}}\right|$ \\
\hline \multicolumn{3}{|c|}{$l=0$} & \multicolumn{3}{|c|}{$l=1$} & \multicolumn{3}{|c|}{$l=2$} \\
\hline 10 & 23 & $17^{*}$ & -22 & & 26 & -6 & 4 & $<9$ \\
\hline 20 & 4 & $<4$ & -12 & 30 & $\mathbf{3 3}$ & -5 & 9 & $<12$ \\
\hline 30 & 42 & 36 & 02 & 1 & $<6$ & -4 & 1 & $<10$ \\
\hline 40 & 13 & 13 & 12 & 14 & 14 & -3 & 7 & $<8$ \\
\hline 50 & 37 & 36 & 22 & 19 & 19 & -2 & 23 & 22 \\
\hline 60 & 12 & 13 & 32 & 12 & 12 & -1 & 7 & 8 \\
\hline 11 & 13 & 12 & 42 & 8 & $<11$ & 0 & 14 & 15 \\
\hline 21 & 20 & 20 & 52 & 5 & $<9$ & 1 & 37 & 32 \\
\hline 31 & 0 & $<5$ & -53 & 5 & $<11$ & 2 & 5 & $<8$ \\
\hline 41 & 28 & 26 & -43 & 37 & 34 & 3 & 13 & 15 \\
\hline 51 & 1 & $<7$ & $-\begin{array}{ll}-3 & 3\end{array}$ & 3 & $<12$ & 4 & 1 & $<13$ \\
\hline 61 & 8 & 10 & -23 & 29 & 29 & 5 & 10 & $<11$ \\
\hline 02 & 17 & 20 & -13 & 30 & $\mathbf{3 0}$ & -6 & 21 & 18 \\
\hline 12 & 13 & 14 & $\mathbf{0} 3$ & 0 & $<8$ & -5 & 30 & $\mathbf{3 1}$ \\
\hline 22 & 61 & $52 *$ & 13 & 55 & 50 & -4 & 12 & $<13$ \\
\hline 32 & 41 & 37 & 23 & 4 & $<9$ & -3 & 22 & 21 \\
\hline 42 & 1 & $<6$ & 33 & 10 & 14 & -2 & 13 & 14 \\
\hline 52 & 26 & 29 & 43 & 35 & 36 & -1 & 60 & $49 *$ \\
\hline 62 & 17 & 17 & 53 & 5 & $<9$ & 0 & 56 & $46 *$ \\
\hline 13 & 25 & 27 & -54 & 13 & 11 & 1 & 10 & 11 \\
\hline 23 & 22 & 20 & -44 & 3 & $<11$ & 2 & 27 & 26 \\
\hline 33 & 3 & $<6$ & -34 & 29 & 29 & 3 & 19 & 18 \\
\hline 43 & 7 & 10 & -24 & 3 & $<13$ & 4 & 25 & 28 \\
\hline 53 & $\mathbf{3}$ & $<6$ & -14 & 2 & $<10$ & 5 & 23 & 25 \\
\hline 0 & 39 & 38 & 04 & 35 & 38 & -5 & 16 & 17 \\
\hline 14 & 25 & 25 & 14 & 4 & $<10$ & $-4:$ & 21 & 22 \\
\hline 24 & 16 & 16 & 24 & 17 & 18 & -3 & 6 & $<10$ \\
\hline 3 & 16 & 17 & 34 & 14 & 15 & -2 & 13 & 14 \\
\hline 44 & 6 & 9 & 44 & 4 & $<10$ & -1 & 14 & 17 \\
\hline 54 & 22 & 20 & -45 & 14 & 13 & 0 & 10 & 10 \\
\hline 15 & 19 & 21 & $\begin{array}{ll}-3 & 5\end{array}$ & 7 & $<11$ & 1 & 14 & 14 \\
\hline 25 & 16 & 16 & -25 & 19 & 20 & 2 & 0 & $<10$ \\
\hline 35 & 20 & 21 & -15 & 20 & 21 & 3 & 22 & 22 \\
\hline 45 & 21 & 18 & 05 & 8 & $<13$ & 4 & 18 & 21 \\
\hline 06 & 16 & 16 & 15 & 16 & 17 & 5 & 3 & $<7$ \\
\hline 16 & 8 & 8 & 25 & 15 & 16 & -5 & 16 & 12 \\
\hline 26 & 12 & 12 & 35 & 18 & 20 & -4 & 14 & 13 \\
\hline & & & -26 & 15 & 14 & -3 & 29 & 29 \\
\hline & & & -16 & 16 & 17 & -2 & 22 & 22 \\
\hline & $=1$ & & 06 & 22 & 21 & $-\overline{1}$ & 14 & 17 \\
\hline & & & 16 & 4 & $<9$ & 0 & 15 & 15 \\
\hline & 19 & 21 & 26 & 21 & 19 & 1 & 12 & 14 \\
\hline & 34 & 32 & & & & & 31 & 32 \\
\hline & 16 & 15 & & & & $\overline{3}$ & 20 & 22 \\
\hline & 48 & $36 *$ & & $=2$ & & 4 & 12 & 14 \\
\hline 1 & 56 & $37 *$ & -60 & 29 & 29 & -4 & 13 & 11 \\
\hline 0 & 23 & 21 & -50 & 15 & 19 & -3 & 4 & $<10$ \\
\hline 11 & 50 & 39 * & -40 & 7 & $<10$ & -2 & 21 & 21 \\
\hline 2 & 35 & 31 & $\begin{array}{ll}-3 & 0\end{array}$ & 75 & $49 *$ & -1 & 22 & 22 \\
\hline 3 & 37 & 34 & -20 & 17 & 15 & 0 & 17 & 17 \\
\hline 4. & 30 & 30 & -10 & 2 & $<5$ & 1 & 20 & 20 \\
\hline & 3 & $<10$ & 00 & 42 & $22 *$ & 2 & 15 & 17 \\
\hline & 7 & $<8$ & 10 & 26 & 23 & $\mathbf{3}$ & 15 & 13 \\
\hline & 12 & 14 & 20 & 66 & $49 *$ & -1 & 13 & 13 \\
\hline & 7 & $<13$ & 30 & 22 & 22 & 0 & 22 & 19 \\
\hline & 2 & $<9$ & 40 & 7 & $<13$ & 1 & 4 & \\
\hline
\end{tabular}


Table 5. Interatomic distances in the $\mathrm{ScO}_{4} \mathrm{~F}_{3}$ polyhedron in $\mathrm{ScOF}$.

\begin{tabular}{|c|c|c|c|c|}
\hline Distance & $\AA$ & $\pm \sigma \AA$ & & Mean distance \\
\hline $\begin{array}{r}S_{1}-F_{3} \\
-F_{1} \\
F_{4}\end{array}$ & $\begin{array}{l}2.13 \\
2.19 \\
2.28\end{array}$ & $\begin{array}{l}0.02 \\
0.02 \\
0.02\end{array}$ & & \\
\hline $\begin{array}{r}\mathrm{Sc}_{1}-\mathrm{O}_{1} \\
-\mathrm{O}_{4} \\
-\mathrm{O}_{3} \\
-\mathrm{O}_{2}\end{array}$ & $\begin{array}{l}2.08 \\
2.08 \\
2.10 \\
2.14\end{array}$ & $\begin{array}{l}0.02 \\
0.02 \\
0.02 \\
0.02\end{array}$ & & 2.20 \\
\hline $\begin{array}{l}\mathbf{F}_{3}-\mathbf{F}_{4} \\
\mathbf{F}_{1}-\mathbf{F}_{4} \\
\mathbf{F}_{1}-\mathbf{F}_{2}\end{array}$ & $\begin{array}{l}2.58 \\
2.74 \\
2.78\end{array}$ & $\begin{array}{l}0.03 \\
0.01 \\
0.02\end{array}$ & (shared edge) & 2.10 \\
\hline $\begin{array}{l}\mathrm{O}_{1}-\mathrm{O}_{2} \\
\mathrm{O}_{2}=\mathrm{O}_{3} \\
\mathrm{O}_{1}=\mathrm{O}_{4} \\
\mathrm{O}_{3}-\mathrm{O}_{4}\end{array}$ & $\begin{array}{l}2.58 \\
2.62 \\
2.62 \\
2.64\end{array}$ & $\begin{array}{l}0.03 \\
0.01 \\
0.01 \\
0.03\end{array}$ & (shared edge) & \\
\hline $\begin{array}{l}\mathbf{F}_{1}-\mathrm{O}_{2} \\
\mathrm{~F}_{4}=\mathrm{O}_{3} \\
\mathrm{~F}_{3}=\mathrm{O}_{1} \\
\mathrm{~F}_{3}=\mathrm{O}_{4} \\
\mathrm{~F}_{4}-\mathrm{O}_{4}\end{array}$ & $\begin{array}{l}2.55 \\
2.55 \\
2.95 \\
2.96 \\
3.03\end{array}$ & $\begin{array}{l}0.02 \\
0.02 \\
0.03 \\
0.02 \\
0.02\end{array}$ & (shared edge) & 2.62 \\
\hline
\end{tabular}

To estimate the influence of absorption on these results the refinements were repeated with the data corrected for the absorption in an untwinned crystal of the same size. However, as this correction yielded no significant changes, it was thought that the differences in the results of the three alternatives from uncorrected data were not dependent upon absorption. Likewise, no significant changes of the original results were obtained by use of the scattering factors for the neutral atoms. ${ }^{4}$

Although the evidence presented which favours the first alternative for the scandium oxide fluoride structure is not strictly conclusive, it appears significant enough in comparison, at least to exclude the two other alternatives.

\section{DISCUSSION OF THE STRUCTURE}

The structure of ScOF thus deduced is shown in Fig. 1. Each scandium atom is surrounded by four oxygen and three fluorine atoms. The coordination polyhedron around the cation and the linking of these polyhedra are the same as in monoclinic $\mathrm{ZrO}_{2}$. The ordered arrangement of oxygen and fluorine atoms is such that the oxygen atoms are part of the fluorite-like layers, described by McCullough and Trueblood for $\mathrm{ZrO}_{2}$.

The interatomic distances within the coordination polyhedron are given in Table 5. The $\mathrm{Sc}-\mathrm{O}$ distances range from 2.08 to $2.14 \AA$ with the average of $2.10 \AA$ and the Sc-F distances from 2.13 to $2.28 \AA$ with the average of $2.20 \AA$. The corresponding averages in $\mathrm{ZrO}_{2}$ are $2.21\left(\mathrm{Zr}-\mathrm{O}_{\mathrm{II}}\right)$ and $2.07 \AA$ 
Fig. 1. Clinographic projection of the ScOF structure.

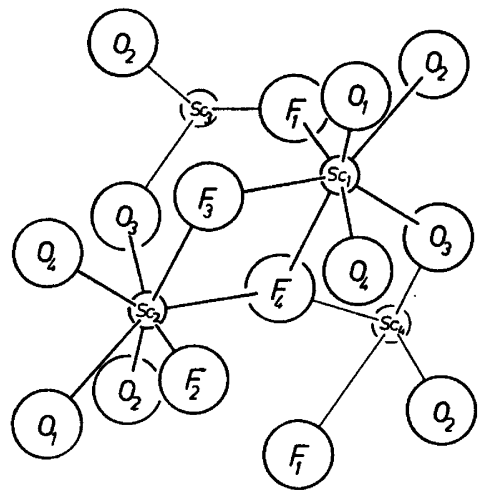

$\left(\mathrm{Zr}-\mathrm{O}_{1}\right)$, these values taken from a recent structure refinement of $\mathrm{ZrO}_{2}{ }^{8}$ Thus, the $\mathrm{Zr}-\mathrm{O}_{\mathrm{I}}$ distance is shorter than the $\mathrm{Zr}-\mathrm{O}_{\mathrm{II}}$ distance while in $\mathrm{ScOF}$ the $\mathrm{Sc}-\mathrm{F}$ distance is longer than the $\mathrm{Sc}-\mathrm{O}$ distance.

All $\mathrm{O}-\mathrm{O}, \mathrm{F}-\mathrm{F}$, and $\mathrm{O}-\mathrm{F}$ distances in the coordination polyhedron are of reasonable length. In particular they are shortened in the expected way for shared edges.

McCullough and Trueblood suggest that the shortening of the $\mathrm{Zr}-\mathrm{O}_{\mathrm{I}}$ distance relative to the $\mathrm{Zr}-\mathrm{O}_{\mathrm{II}}$ distance may be a result of the electrostatic imbalance at each corner of the $\mathrm{Zr}$ coordination polyhedron. Thus, at the corner occupied by $\mathrm{O}_{\mathrm{I}}$, triangularly surrounded by three zirconium atoms, the value of $\sum s=\sum \frac{z}{v}=3 \cdot \frac{4}{7}=\frac{12}{7}$ and at the corner occupied by $\mathrm{O}_{\mathrm{II}}$, tetrahedrally surrounded by four zirconium atoms, $\sum s=4 \cdot \frac{4}{7}=\frac{16}{7} .^{2}$ Both these values are to be compared with -2 , the charge of the oxygen ion. Thus, there are deviations from the electrostatic valence rule ${ }^{9}$ amounting to $\pm \frac{2}{7}$ at each corner.

The value of $\sum s$ for $\mathrm{ScOF}$ at the two types of corners are $3 \cdot \frac{3}{7}=\frac{9}{7}\left(\mathrm{~A}_{\mathrm{r}}\right)$ and $4 \cdot \frac{3}{7}=\frac{12}{7}\left(\dot{A}_{11}\right)$. These values are to be compared with -1 and -2 , the charges of fluorine and oxygen ions. With this anion arrangement the electrostatic imbalance will favour a shortening of the $\mathrm{Sc}-\mathrm{A}_{\mathrm{II}}$ distance relative to the $\mathrm{Sc}-\mathrm{A}_{\mathrm{I}}$ distance. For the other two anion arrangements discussed, where the corresponding charges would be -2 and -1 (alternative 2) and -1.5 and -1.5 (alternative 3 ), the electrostatic imbalance would favour in the same way as in $\mathrm{ZrO}_{2}$ a shortening of the $\mathrm{Sc}-\mathrm{A}_{\mathrm{r}}$ distance relative to the $\mathrm{Sc}-\mathrm{A}_{\mathrm{II}}$ distance.

In $\mathrm{Sc}_{2} \mathrm{O}_{3}$, where the oxygen atoms are surrounded tetrahedrally by four scandium atoms but where the scandium atoms are only coordinated by six oxygens, the average $\mathrm{Sc}-\mathrm{O}$ distance was found to be $2.122 \AA$. $^{10}$ The Sc-F distance has been reported to be $2.02 \AA$ in $\mathrm{ScF}_{3}$, which has a distorted $\mathrm{ReO}_{3}$

Acta Chem. Scand. 20 (1966) No. 4 
structure with scandium octahedrally coordinated by fluorine. ${ }^{11} \mathrm{~A}$ comparison between these figures and $2.10\left(\mathrm{Sc}-\mathrm{A}_{11}\right)$ and $2.20 \AA\left(\mathrm{Sc}-\mathrm{A}_{1}\right)$, the observed distances in $\mathrm{ScOF}$, reveals that these distances are in accordance with the effect of the electrostatic imbalance resulting from oxygen atoms in the $A_{I I}$ position and fluorine atoms in the $A_{I}$ position, the same anion arrangement as deduced from the refinement procedures.

Acknowledgements. The author wishes to thank Professor A. Magnéli for his continuous interest in this work and for his valuable comments on the manuscript and Dr. P. Moore for correcting the English. Thanks are due to the Computer Division of the National Swedish Rationalization Agency for the use of the computers BESK and FACIT EDB. The investigation has been supported financially by the Swedish Natural Science Research Council.

\section{REFERENCES}

1. Yardley, K. Mineral. Mag. 21 (1926) 169.

2. McCullough, J. D. and Trueblood, K. N. Acta Cryst. 12 (1959) 507.

3. Adam, J. and Rogers, M. D. Acta Cryst. 12 (1959) 951.

4. Åsbrink, S. and Brändén, C. List of Crystallographic Computer Programs (1962), Accession number 6023 .

5. International Tables for X-ray Crystallography, Vol. III, Birmingham 1962, Table 3.3. 1A.

6. Suzuki, J. Acta Cryst. 13 (1960) 279.

7. Hughes, E. W. J. Am. Chem. Soc. 63 (1941) 1737.

8. Smith, D. K. and Newkirk, H. W. Acta Cryst. 18 (1965) 983.

9. Pauling, L. J. Am. Chem. Soc. 51 (1929) 1010.

10. Norrestam, R. To be published.

11. Nowacki, W. Z. Krist. 101 (1939) 273.

Received December 9, 1965. 